\title{
Social Networking Sites - a necessary evil
}

\author{
Bhakti Shah $^{1}$, Devanshi Mehta ${ }^{1}$, Rakhi Mehta ${ }^{2}$ \\ ${ }^{1}$ TYBA Student, ${ }^{2}$ Assistant Professor, \\ Department of Psychology, K.C. College, Mumbai \\ Corresponding author: Bhakti Shah \\ Email-bhaktinshah@gmail.com
}

\begin{abstract}
Background: Explosive growth of Social Networking Sites (SNS) have impacted every sphere of a youths life be it academics or personal relationships. There has been an escalation of research worldwide in this area though it is negligible in India. The present research seeks to fulfil this lacuna by studying the impact of SNS use on sleep, academic achievement, concentration, self esteem and personal relationships on Indian youth.

Methodology: The sample consisted of students from junior and degree colleges in Mumbai belonging to the age group of 16 to 22 years, equal number of male and female students was selected. They were administered a self-formulated questionnaire consisting of 24 questions, which measured their SNS use habits and its impact on sleep, academics, concentration, self esteem and social relationships in terms of gender differences and education level. The scores obtained were subjected to ' $t$ ' test. A significant ' $t$ ' value of was found for gender differences but not for junior and degree college students.

Results: Results indicated that the bio-psychosocial factors of males were affected more by SNS use than the females and there was no difference in the impact of bio-psychosocial factors of junior and degree college students who were SNS users. The mean scores were 16.60, 16.32 and 15.64 for academics/sleep/concentration, relationship and self esteem respectively. Hence the maximum impact of SNS use was seen on academic/sleep/concentration followed by relationship and lastly self esteem.

Conclusions: Thus, the burgeoning nature of SNS does impact the youth in some aspects of their life as it has become a core of all the forms of communication.
\end{abstract}

Keywords: social networking sites, self esteem, .

(Paper received $-19^{\text {th }}$ December 2017, Peer review completed $-9^{\text {th }}$ March 2018)

(Accepted $-10^{\text {th }}$ March 2018)

\section{INTRODUCTION}

The Internet has evolved into a speedy and easy mode of communication, which has created a platform for various websites which help people communicate with each other from any part of the world. These communicating websites are known as Social Networking Sites (SNS) which are today a phenomenon across the world. 'Social networking sites' are interactive modes of communication which are web based services that allow individuals to (1) construct a public or semi public profile within a bounded system,(2) articulate a list of other users with whom they share a connection and (3) view and traverse their list of connection and those made by others within the system [1]. SNS have not only become popular but also are a part of daily life of increasing number of people, mainly youth. Unfortunately, even though such sites can be used for meaningful or educational interaction, youth are engaging in only non educational and inappropriate actions including useless chatting [2].

A research by Lenhart and Madden [3] revealed through a survey that students strongly recommended SNS to stay in touch with their friends, to be informed and aware. According to recent poll $22 \%$ of 
teenagers log on to their SNS more than 10 times a day and more than half of the adolescents log on to SNS more than once a day. Thus a large part of these generations social and emotional development is occurring while on the internet. Because of their limited capacity for self regulation and susceptibility to peer pressure children and adolescents are at some risk as they navigate and experiment with the social media.

The proliferation of Social Networking Sites has created a phenomenon that engages millions of internet users around the world, especially young people. These sites have an impact both bad and good; especially on the youth aged between 16-22 years. This has lead to an escalation in research linking Social Networking sites with academics, sleep disturbance, relationships and self esteem. The studies related to these are cited below.

\section{Social Networking Sites and Academics}

Many parents are worried that their college going children are spending too much time on Social Networking Sites and not enough time studying. This is supported by a research which has found that college students using popular networking sites study for less time [4] and have lower grade point averages than students who do not use these sites [5]. Two thirds of students in a research reported using electronic media while in class, studying or doing homework [6]. 57\% students agreed to the fact that Social Networking Sites use has made them less productive. 483 first year college women surveyed indicated spending over 12 hours a day texting using social media which led to worse grades and bad academic performance (Miriam Hospital). Education researchers have found link between Social Networking Sites use, students' academic engagement and achievement [7-9]. A reason for Social Networking Sites hindering academic achievement can be its negative impact on sleep disturbances and concentration.

\section{Social Networking Sites, Sleep Disturbances and Concentration Levels}

Exposure to bright light from computer and mobile phones in bed disrupts body's circadian rhythm and also the ability to fall asleep [10]. This is because according to a survey a staggering $95 \%$ of the respondents used Social Networking Sites before bed time and $40 \%$ had regular text communication with friends during bed time. Teenagers spend an average 3-4 hours on social media each night (Cheshire, UK, 2014). Youth using technology suffer from insomnia and fail to experience a deep REM sleep (a time when brain processes memories and learns from previous day). Social media was found to be the main reason behind students' tiredness at school which in turn affected concentration. Teenagers using phone between midnight and 3a.m. were four times tired. Youth check their Social Networking Sites messages very frequently, are anxious if unable to do so [11] and suffer from Phantom Vibration Syndrome [12]. Social Networking Sites are addictive and lead to "a fear of missing out" called as "FOMO" by students. Wintour in his article 'Facebook and Beborist infantilizing the human mind' says Social Networking Sites are putting attention span of youth in jeopardy. Since youth are so obsessed with Social Networking Sites it can have a detrimental impact on their self esteem.

\section{Social Networking Sites and Self Esteem}

Numerous studies have linked Social Networking Sites to depression, social isolation, eliciting feelings of envy, insecurity and poor self esteem [13]. Volkenburg and others [14] found a relation between Social Networking Sites use and self esteem in a sample of over 800 Dutch adolescents. $50 \%$ of the 298 participants in a study linking Social Networking Sites to self esteem, reported worst lives after the use of Social Networking Sites. Focus on close friends in Social Networking Sites lead to an increase in self esteem. Schouten and others [15] in a study on Dutch youth found that positive feedback on Social Networking Sites lead to enhanced self esteem. Also youth with low self esteem use Social Networking Sites more often to relieve themselves from social anxiety manifested in face to face interactions. Thus self esteem, Social Networking Sites and relationships seem to be closely linked.

\section{Social Networking Sites and Relationships}

Socializing via the internet has increasingly become important part of young adult life [16]. Though staying in touch with current friends and family via Social Networking Sites is popular, it is also used for 
making new friends and finding potential romantic partners [17]. Approximately $91 \%$ of Social Networking Sites users mainly youth utilize the sites to communicate with already known friends. But Social Networking Sites use rarely brings youth as close as it does in a face to face interaction [18], as they are unable to express their emotions clearly via the internet [19] Social Networking Sites also impacts the privacy of relationships as they are visible to many [20]. Thus this exacerbates relationship problems that would have been better handled offline. Studies have found a positive correlation between internet use and face to face involvement of college students [21]. Similarly students receiving positive comments on Social Networking Sites reported good adjustment.

\section{Social Networking Sites and Gender Differences}

Gender appears to influence participation on Social Networking Sites. Younger or junior college boys participate more than younger or junior college girls whereas older or degree college girls participate more than degree college or older boys. Degree college or older boys use Social Networking Sites to flirt or make new friends whereas degree college or older girls use Social Networking Sites to connect with people whom they meet in person [1]. Girls are more preoccupied about comments they receive from friends on Social Networking Sites [3] and make more emotionally supportive comments online than males [22]. A Finnish study on youth indicated gender differences on the impact of Social Networking Sites use on sleep and health. The mobile phone usage was more for girls which led to sleep impairment.

\section{Research Studies in India}

According to the recent poll done in India $22 \%$ of teenagers, log on to Social Networking Sites for more than 10 times a day. Thus, a large part of this generation's social and emotional development is occurring while on the internet. Social Networking Sites grab attention of students and then it diverts them towards non educational and inappropriate actions using useless chatting [2]. In a study on Indian youth considering the disadvantages of Social Networking Sites, Indian youth admitted a lot of waste of time on these sites, and the time consuming nature of these sites.

The research studies point to the impact of SNS on various aspects of life. The present study investigates the impact of SNS specifically on the youth population.

\section{METHODOLOGY}

SNS has rapidly gained prominence in the last decade. The worldwide proliferation of such sites and the increasing number of youth joining these sites, they are undoubtedly playing a fundamental role in the younger generation's daily life functioning. Thus, in order to evaluate this phenomenal activity, the researchers have embarked on this study to get an insightful knowledge of the SNS usage pattern and its impact on youth's bio-psychosocial factors in terms of sleep, academics, concentration, relationships and self-esteem.

\section{Objectives}

The objectives of the study are as follows:

1. To determine the nature/pattern of SNS use by youth [college students] users.

2. To evaluate the affect of SNS use on youth's sleep, academics, concentration, self esteem and relationships.

3. To identify the difference between male \& female college students regarding their SNS use and its impact on their bio-psychosocial factors.

4. To identify the difference between junior/degree college students on their SNS usage pattern and its impact on their bio-psychosocial factors. 


\section{Research Variables}

Independent Variable - The independent variable in the study is frequency of SNS use

Dependent Variable - The dependent variables in the study are the bio-psychosocial factors namely self esteem, social relationships, sleep deprivation, academic performance and concentration.

\section{Hypothesis}

The study tests the following hypothesis:

1. There will be no difference in the bio-psychosocial factors between male and female student users of social networking sites.

2. There will be no difference in the bio-psychosocial factors between junior and degree college student users of social networking sites.

3. Frequency of SNS use will have the greatest impact on academics/sleep/concentration, followed by self esteem and social relationships among the college students.

\section{Control Variables}

The control variables chosen for the study are:

1. Age - The participants chosen for the study were between the age group of 16-22 years.

2. Gender - Male and female college students were randomly selected in equal numbers (i.e. 50:50).

3. Educational Qualification - The participants selected in the study were junior and degree college students in equal numbers (i.e.50:50) currently belonging to arts, science and commerce streams.

4. The students were studying in colleges across Mumbai.

5. The participants in the study were selected only if they were users of social networking sites.

\section{Sample}

The sample (participants) for the study were selected randomly across the campuses of different colleges in Mumbai. The total sample size was 100 college going students using SNS and were in the age group of 1622 years of age. In the sample equal numbers of male and female students (50:50) and equal numbers of junior and degree college students (50:50 where, 25:25 are junior college male \& female students and 25:25 are degree college male \& female students respectively), studying in streams of arts, science and commerce.

\section{Tools Used}

A self-formulated questionnaire was administered for the purpose of collecting data, to determine the nature of SNS use and its impact on youth users. The questionnaire collected some demographic information about the participants i.e. age, gender and educational qualification, followed by 5 open-ended questions to know the basic background about the participants SNS usage. 24 main close-ended questions related to each variable were chosen in the study ( 8 questions for each variable) with the options 'Always, Sometimes, and Never' which were scored on the scale of 3, 2, and 1 respectively where the lowest score a participant can receive is 8 and the highest score a participant can receive is 24 (for each variable).

\section{Procedure}

Questionnaires were distributed either as hard copies or electronically, for electronic copies the researchers used Google E-Forms. Prior to the main survey, a pilot study was conducted on 5 randomly selected college students and required changes were incorporated according to the feedback. The researchers randomly choose 40 participants (equal number of male/female and junior/degree college students) from campuses of colleges across Mumbai which were given hard copies of the questionnaire. The other 60 participants were given E-questionnaires online via email, Facebook and Whatsapp; these participants were randomly chosen from researchers contact list. No time limit was allotted to fill in the questionnaire; doubts-queries were clarified by the researchers. The responses of the participants were kept confidential and used only for research purposes. 
The detrimental effects of SNS use by the youth on their bio-psychosocial factors is been measured in the present study on the basis of a survey. The survey was scored, several ' $t$ ' tests and measures of central tendency (Mean) was calculated. Graphical representation of results was provided.

\section{RESULTS AND DISCUSSION}

\section{Demographic Data}

The age of respondents were categorized in two age groups i.e. 16-19 years (late adolescent phase) and 2022 years (early adulthood). 82 respondents were in the age group of 16-19 years and 18 belonged to the age group of 20-22 years. Hence, this indicated that majority were part of the late adolescents phase. According to Lin and Subrahmanyam [23], adolescents are the greatest consumers of the internet especially for assessing SNS. These SNS's have changed the way adolescents (students) interact and gather information [24]. Thus, age was considered a prominent factor in the present study. The figure below shows the graphical representation of the age. Out of a sample size of 100 , equal number of males and female i.e. 50 each were administered on a survey. The gender of the respondent was considered a vital factor as several previous researches have cited the impact of gender variances in SNS usage pattern and its impact on them. Research by Boyd and Ellison [1], Lenhart [3], Baron [24] and many others have found gender difference in terms of their SNS use.

The educational qualifications were asked to the respondents in the survey, where the students belonged to junior and degree College (50 each) in the streams of arts, commerce and science. However, the education qualification was not taken into consideration in the study as an important factor to link with SNS.

The second part of the questionnaire collected information about SNS habits of the sample -

1. The Length of SNS Use: The length of SNS use was measured in terms of months or years of use. Out of 100 participants, 76 respondents were using SNS for 0-5 years and 24 were using SNS for 6-10 years.

2. The Frequency Of SNS Use: The frequency of use is measured in terms of number of hours they spent daily on SNS. 20 respondents spent $1 \mathrm{hr}, 47$ spent $2-5 \mathrm{hrs}, 27$ spent $5-10 \mathrm{hrs}$ and 6 spent above $10 \mathrm{hrs}$ per day on SNS. The frequency of SNS use is a significant aspect of the study as it has a major impact on youth.

3. Popular Social Networking Sites: The social networking sites frequently used by the students were Whatsapp (25.14\%), Facebook (24.26\%), Hike (12.28\%), Instagram (11.98\%), Snapchat (6.14\%), Twitter (4.38\%) and other SNS's accounted for 15.78\% (like Viber, Wechat, Hangout, BBM, Skype, Myspace, and many more). All of these sites vary in their functioning, layouts and features.

SNS has an integral role in a youth's life which also affects their daily processes. The present study aims at evaluating the impact of SNS on youth's bio-psychosocial factors on basis of a survey. The survey was conducted through a self-formulated questionnaire measuring all the variables of the present study. (including 24 main questions where 8 questions were allotted to each of the variable)

1. Relationships: $12 \%$ of respondents were affected least, $73 \%$ of respondents were affected moderately and $15 \%$ experienced the greatest impact on their relationships due to SNS use.

2. Sleep and Academics: $11 \%$ from the total respondents were affected the least, $78 \%$ were affected moderately and $11 \%$ were affected most on academic, sleep and concentration by the use of SNS.

3. Self esteem: $22 \%$ were affected the most, $72 \%$ were affected moderately and $6 \%$ were affected more on self esteem by SNS use.

A significant ' $t$ ' value (2.07) was obtained for differences in bio-psychosocial factors of male and female SNS users. Thus the male students will be affected more than the female students by frequency of SNS use, which is in line with several researchers who have found differences in male and female SNS users $[1,3$, 25]. A non significant ' $t$ ' value (-0.76) was obtained for differences in bio-psychosocial factors of junior and degree college SNS users. Therefore there was no difference between them, in terms of impact of SNS use. 


\section{CONCLUSION}

Social networking sites have altered how youth socialize and learn. There are new sets of issues raised for educators, parents, researchers and policy makers. Participation in the socially networking world and understanding its consequences, teens moral and ethical online presence is necessary. SNS is definitely having an impact on the development of academics, sleep, self esteem, social relationships, and is a major factor causing bio psychosocial problems. Perhaps, the next time one goes to check one's phone for SNS messages in the middle of night or while studying or during lectures and also taking online comments seriously, one should have a rethink, because of its great impact. Maybe one should use it at a conscious level.

\section{REFERENCES}

1. Boyd DM, Ellison NB. Social network sites: Definition, history, and scholarship. J Computer Mediated Communication 2007;13(1):210-30.

2. Kuppuswamy S, Narayan P. The Impact of Social Networking Websites on the Education of Youth. International Journal of Virtual Communities and Social Networking 2010;2(1):67-79.

3. Lenhart A, Madden M. Teens, privacy \& online social networks: How teens manage their online identities and personal information in the age of MySpace. Pew Internet \& American Life Project; 2007.

4. Newman MW, Lauterbach D, Munson SA, Resnick P, Morris ME. It's not that i don't have problems, i'm just not putting them on facebook: challenges and opportunities in using online social networks for health. InProceedings of the ACM 2011 conference on Computer supported cooperative work 2011 Mar 19 (pp. 341350).

5. Karpinski AC, Kirschner PA, Ozer I, Mellott JA, Ochwo P. An exploration of social networking site use, multitasking, and academic performance among United States and European university students. Comp Hum Behav 2013;29(3):1182-92.

6. Jacobsen WC, Forste R. The wired generation: Academic and social outcomes of electronic media use among university students. Cyberpsychol Behav Soc Network 2011;14(5):275-80.

7. Eccles JS, Templeton J. Extracurricular and other after- school activities for youth. Rev Res Education 2002;26:113-80.

8. Feldman AJ, Blankstein A, Freedman MJ, Felten EW. Social Networking with Frientegrity: Privacy and Integrity with an Untrusted Provider. InUSENIX Security Symposium 2012 Aug 8 (pp. 647-662).

9. Martin C. Social networking usage and grades among college students. UNH Media Relations, University of New Hampshire. UNH Whittemore School of Business and Economics ; 2009.

10. $\mathrm{Ng} \mathrm{BD}$, Wiemer-Hastings $\mathrm{P}$. Addiction to the internet and online gaming. Cyberpsychol Behav 2005;8(2):110-3.

11. Rosen LD, Carrier LM, Cheever NA. Facebook and texting made me do it: Media-induced task-switching while studying. Comp Hum Behav 2013;29(3):948-58.

12. Kietzmann JH, Hermkens K, McCarthy IP, Silvestre BS. Social media? Get serious! Understanding the functional building blocks of social media. Business Horizons 2011;54(3):241-51.

13. Durlofsky P. Can Too Much Social Media Cause Depression. Main Line Today. NP Feb 2014.

14. Valkenburg PM, Peter J, Schouten AP. Friend networking sites and their relationship to adolescents' wellbeing and social self-esteem. Cyberpsychol Behav 2006;9(5):584-90.

15. Steijn WM, Schouten AP. Information sharing and relationships on social networking sites. Cyberpsychol Behav Soc Network 2013;16(8):582-7.

16. Gemmill EL, Peterson M. Technology use among college students: Implications for student affairs professionals. NASPA Journal 2006;43(2):280-300.

17. Smith A. Why Americans use social media. Pew Internet and American Life Project 2011;15:1-1.

18. Mesch GS. Minority status and the use of computer-mediated communication: A test of the social diversification hypothesis. Communication Research 2012;39(3):317-37.

19. Asilo JM, Manlapig JA, Rementilla JJ. The influence of social networking sites on the interpersonal relationships of Rogationist College students. Research Proposal www. scribd. com retrieved on. 2016:7.

20. Muscanell NL, Guadagno RE. Make new friends or keep the old: Gender and personality differences in social networking use. Comp Hum Behav 2012;28(1):107-12.

21. Lampe C, Ellison N, Steinfield C. A Face (book) in the crowd: Social searching vs. social browsing. InProceedings of the 2006 20th anniversary conference on Computer supported cooperative work 2006 Nov 4 (pp. 167-170). ACM.

22. Lin KY, Lu HP. Why people use social networking sites: An empirical study integrating network externalities and motivation theory. Comp Hum Behavior 2011;27(3):1152-61.

23. Ben Mokhtar S, Capra L. From pervasive to social computing: algorithms and deployments. InProceedings of the 2009 international conference on Pervasive services 2009 Jul 13 (pp. 169-178). ACM. 
24. Podolny JM, Baron JN. Resources and relationships: Social networks and mobility in the workplace. Amer Sociolog Rev 1997;1:673-93.

$* * * * * * * * * * * * * * * * * * * * * * *$

Acknowledgements - Nil

Conflict of Interest - Nil

Funding - Nil 